\title{
THE CORRELATION OF PARENTING STYLE WITH UNDERGRADUATE MEDICAL STUDENTS' ACADEMIC INTEGRITY IN A MEDICAL SCHOOL
}

\author{
Puspa Maharani, Hikmah Muktamiroh, Lasma Nurhayati \\ Fakultas Kedokteran Universitas Pembangunan Nasional "Veteran", Jakarta - INDONESIA
}

\begin{abstract}
Background: Academic integrity is one of the main principle in academic culture. Academic integrity, defined as obedience to the principle in academic sphere. However, violation to the academic principle is a common phenomenon occurred in the high education. Integrated academic is closely related to morality, while morality is highly influenced by the parenting method. This study aimed to find relationship between parenting method and academic integrity behavior of student in academic stage of Medical Faculty.

Method: This study conducted using proportional stratified random sampling with total sample of 225 medical students, the data from this study was collected from the questionnaire. The design was cross sectional method. Data was analyzed using Chi-Square test.

Results: From Chi-Square test, the result for $P$ Value was $P=0.011$, which means it was below $P<0,05$.

Conclusion: We can conclude that there is meaningful correlation between parenting method with academic integrity behavior of student in academic stage of Medical Faculty.
\end{abstract}

Keywords: parenting, academic integrity, medical student

\section{ABSTRAK}

Latar belakang: Integritas akademik merupakan hal yang utama dalam budaya akademik dan diartikan sebagai suatu kepatuhan terhadap prinsip-prinsip dasar di dunia akademik. Namun, pelanggaran terhadap integritas akademik yang dilakukan oleh mahasiswa masih merupakan masalah tersendiri di dalam dunia pendidikan saat ini. Integritas akademik erat kaitannya dengan moral, dan perilaku moral seseorang dapat dibentuk dari pengasuhan oleh orang tua. Penelitian ini bertujuan untuk mengetahui korelasi pola asuh orang tua dengan perilaku integritas akademik mahasiswa Fakultas Kedokteran tahap akademik.

Metode: Penelitian ini menggunakan proportional stratified random sampling dengan jumlah sampel 225 mahasiswa Fakultas Kedokteran tahap akademik dari hasil pengambilan data dengan kuisioner. Desain penelitian yang dilakukan adalah metode cross sectional. Analisis data pada penelitian ini menggunakan uji Chi-Square.

Hasil: Dari hasil uji statistik yang dilakukan dengan menggunakan uji Chi- Square didapatkan hasil $\mathrm{p}=$ 0,011 . Dengan demikian berarti nilai $\mathrm{p}<0,05$.

Kesimpulan: Terdapat korelasi yang bermakna antara pola asuh orang tua dengan integritas akademik mahasiswa Fakultas Kedokteran tahap akademik.

Kata kunci: pola asuh, integritas akademik, mahasiswa kedokteran

contact: puspa_maharani@ymail.com; hikmah.fkupnvj@gmail.com 


\section{PENDAHULUAN}

Integritas akademik merupakan hal yang utama dalam budaya akademik dan diartikan sebagai suatu kepatuhan terhadap prinsip-prinsip dasar di dunia akademik. Prinsip-prinsip tersebut adalah kejujuran akademik, saling percaya, keterbukaan, saling menghormati, dan rasa bertanggungjawab. ${ }^{1}$ Kelima prinsip tersebut harus dapat dipegang teguh dan dipatuhi oleh seluruh kalangan akademik, salah satunya adalah mahasiswa.

Namun, pelanggaran terhadap integritas akademik yang dilakukan oleh mahasiswa masih merupakan masalah tersendiri di dunia pendidikan saat ini, tak terkecuali mahasiswa kedokteran. Banyak hasil penelitian yang menggambarkan bahwa pelanggaran integritas akademik di kalangan mahasiswa masih cukup tinggi. Penelitian yang dilakukan di Teheran oleh Hejri, Zendehdel, Asghari, Fotouhi dan Rashidian. ${ }^{2}$ Pada penelitian yang menggunakan tehnik randomized response ini ditemukan beberapa bentuk pelanggaran integritas akademik pada mahasiswa tahap klinis (mahasiswa tahun ke 4-5) dan tahap internship (mahasiswa tahun ke 6-7). Menyontek, plagiarisme, manipulasi data (misalnya riwayat pasien), kecurangan pada shift jaga dan pelanggaran lain juga masih kerap terjadi. ${ }^{2}$ Pada penelitian yang dilakukan oleh Taradi dan Dogas di Kroasia, ditemukan bahwa pelanggaran integritas akademik lazim terjadi di sekolah kedokteran di Kroasia, bahkan dipandang sebagai perilaku yang dapat diterima oleh calon dokter Kroasia di masa mendatang. ${ }^{3}$

Banyak alasan yang melatarbelakangi terjadinya pelanggaran integritas akademik, antara lain ketidaktahuan mengenai peraturan dan etika yang berlaku, ketakutan tujuannya tidak tercapai, serta keinginan mencapai kesuksesan tanpa mau berusaha keras sehingga melanggar prinsip-prinsip dasar yang harus dipenuhi. ${ }^{1}$ Pelanggaran terhadap prinsip-prinsip dasar yang harus dipenuhi tersebut merupakan masalah penting, karena seorang mahasiswa kedokteran di masa depan diharapkan dapat berkembang menjadi seorang dokter yang dituntut untuk bersikap profesional. ${ }^{4}$

Berdasarkan panduan perilaku profesional dokter dan mahasiswa kedokteran yang dirumuskan oleh General Medical Counsil,,$^{5}$ dapat dilihat bahwa nilai- nilai profesionalisme pada dokter dan mahasiswa kedokteran tidak berbeda jauh. Beberapa perilaku yang diharapkan dapat terbentuk di dalam diri mahasiswa kedokteran antara lain adalah honesty, respect, fairness, responsibility, trust ${ }^{6}$ dan hal ini sesuai dengan prinsip-prinsip integritas akademik yang dinyatakan oleh The International Center for Academic Integrity. Integritas akademik adalah hal yang penting, karena integritas akademik yang dimiliki mahasiswa sejak masa pendidikan merupakan salah satu komponen yang mempengaruhi perilaku profesional saat bekerja. ${ }^{7}$ Oleh karena itu, penting untuk terus melakukan evaluasi terhadap integritas akademik mahasiswa dan mencari faktor-faktor yang mempengaruhi tinggi maupun rendahnya integritas akademik yang dimiliki mahasiswa.

Integritas akademik erat kaitannya dengan moral, mengingat bahwa integritas akademik berisi tentang prinsip-prinsip yang harus dipenuhi. Terlaksana atau tidaknya prinsip-prinsip tersebut bergantung pada perilaku moral yang dimiliki oleh masing-masing mahasiswa. Hal ini dikarenakan perilaku moral merupakan perilaku seseorang dalam menjalankan prinsip-prinsip yang ada di dalam masyarakat. ${ }^{8}$ Perilaku moral seseorang dapat dibentuk dari pengasuhan oleh orang tua. Pengasuhan seseorang oleh orang tua, memiliki pola yang berbeda-beda. Penggunaan pola asuh yang berbeda-beda ini menyebabkan munculnya variasi perkembangan atas perilaku-perilaku tertentu pada anak tergantung dari pola asuh yang diterapkan. ${ }^{9}$ Sehingga, dapat dihipotesakan bahwa pola pengasuhan orang tua sangat mempengaruhi perilaku moral seseorang.

Berdasarkan hal-hal yang telah dijabarkan sebelumnya, dapat dilihat bahwa ada kemungkinan pola asuh orang tua merupakan salah satu faktor yang berhubungan dengan perilaku integritas akademik mahasiswa. Oleh karena itu, peneliti tertarik melakukan penelitian tentang korelasi pola asuh orang tua dengan perilaku integritas akademik mahasiswa Fakultas Kedokteran Penelitian dilakukan di suatu Fakultas Kedokteran di Indonesia dengan harapan dapat memberikan kontribusi keilmuan yang berguna untuk peningkatan perilaku integritas akademik di Fakultas Kedokteran. 


\section{METODE}

Penelitian ini adalah merupakan penelitian analitik yang bertujuan mencari hubungan antara variabel independen dengan variabel dependen. ${ }^{9}$ Variabel independen pada penelitian ini adalah pola asuh orang tua sedangkan variabel dependen pada penelitian ini adalah perilaku integritas akademik. Desain penelitian yang dilakukan untuk pengambilan data adalah metode cross-sectional, yaitu peneliti melakukan observasi atau pengukuran variabel di satu waktu tertentu. ${ }^{10}$ Populasi pada penelitian ini adalah mahasiswa Fakultas Kedokteran tingkat 1, 2, dan 3 yang berjumlah 513 mahasiswa. Pengambilan sampel dilakukan dengan menggunakan teknik proportional stratified random sampling berdasarkan strata tingkat pendidikan mahasiswa di Fakultas Kedokteran. Penentuan jumlah sampel dilakukan menggunakan rumus Slovin sehingga jumlah sampel penelitian yang dibutuhkan menjadi sebanyak 225 mahasiswa. Kriteria inklusi pada penelitian ini adalah mahasiswa pre klinik Fakultas Kedokteran tingkat 1, 2 dan 3, sedang kriteria eksklusi adalah mahasiswa berstatus yatim piatu, diasuh oleh orang tua angkat atau diasuh oleh anggota keluarga selain orang tua kandung.

Jenis data yang digunakan adalah data primer. Data primer untuk integritas akademik dikumpulkan dengan menggunakan instrumen kuesioner Roff edisi Indonesia yang dimodifikasi untuk mahasiswa pre klinik yang sudah dilakukan uji validitas dan reliabilitasnya. Kuesioner integritas akademik yang menggunakan skala Likert dinyatakan valid dengan dengan range $r$ hitung 0.144-0.558 dan dinyatakan reliabel dengan Cronbach Alpha 0.818. Kuesioner pola asuh merupakan kuesioner dengan skala Likert, dinyatakan valid dengan range $r$ hitung untuk kuesioner pola asuh otoriter 0.473 0.810, pola asuh demokratis $0.439-0.679$, dan pola asuh permisif 0.370-0.782. Kuesioner pola asuh dinyatakan reliabel dengan Cronbach Alpha 0.786 untuk kuesioner pola asuh otoriter, Cronbach Alpha 0.656 untuk pola asuh demokratis, dan Cronbach Alpha 0.622 untuk pola asuh permisif.

Penelitian ini menggunakan analisis data univariat dan bivariat. Analisis univariat digunakan untuk mengetahui distribusi frekuensi variabel independen dan dependen yang diteliti. Analisis bivariat digunakan untuk mengetahui ada tidaknya korelasi antara variabel independen dengan variabel dependen. Pada penelitian ini, seluruh variabel yang diteliti merupakan data kategorik tidak berpasangan dengan tabel $\mathrm{n} \times \mathrm{k}(3 \times 3)$, sehingga uji yang dilakukan adalah uji Chi square.

Penelitian dilakukan setelah mendapatkan informed consent yang dilakukan sebelum pengambilan data dan mendapatkan persetujuan (ethical clearance) dari Komite Etik Penelitian Universitas Pembangunan Nasional.

\section{HASIL DAN PEMBAHASAN}

\section{Karakteristik responden}

Karakteristik responden berdasar usia dan tingkat pendidikan di Fakultas Kedokteran dijelaskan pada tabel 1 dan 2 berikut ini:

Tabel 1. Jumlah Responden berdasar tingkat pendidikan di Tahap akademik

\begin{tabular}{ccc} 
Tingkat pendidikan & Frekuensi & Persentase (\%) \\
Tingkat 1 & 75 & 33.3 \\
Tingkat 2 & 71 & 31.6 \\
Tingkat 3 & 79 & 35.1 \\
\hline Total & 225 & 100 \\
\hline
\end{tabular}

Tabel 1 menunjukkan jumlah dan persentase responden pada masing-masing tingkat. Tingkat 1 memiliki perentase 33,3\%, Tingkat 2 memiliki persentase $31,6 \%$ dan tingkat 3 memiliki persentase $35,6 \%$.

Tabel 2. Jumlah Responden berdasar usia

\begin{tabular}{ccc} 
Usia & Frekuensi & Persentase (\%) \\
Usia 17 tahun & 2 & 0.9 \\
Usia 18 tahun & 28 & 12.4 \\
Usia 19 tahun & 69 & 30.7 \\
Usia 20 tahun & 69 & 30.7 \\
Usia 21 tahun & 45 & 20.0 \\
Usia 22 tahun & 12 & 5.3 \\
\hline Total & 225 & 100 \\
\hline
\end{tabular}

Tabel 2 menunjukkan jumlah dan persentase responden berdasarkan usianya. Responden yang berusia 17 tahun berjumlah 2 orang atau $0.9 \%$, 
responden yang berusia 18 tahun berjumlah 28 orang atau $12.4 \%$, responden yang berusia 19 tahun berjumlah 69 orang atau $30.7 \%$, responden yang berusia 20 tahun berjumlah 69 orang atau 30.7\%, responden yang berusia 21 tahun berjumlah 45 orang atau $20 \%$, dan responden yang berusia 22 tahun berjumlah 12 orang atau 5.3\%.

\section{Analisis univariat}

Analisis ini dilakukan untuk mengetahui gambaran dan distribusi dari variabel-variabel penelitian, yaitu pola asuh orang tua sebagai variabel dependen dan perilaku integritas akademik sebagai variabel independen.

Tabel 3. Distribusi Pola Asuh Orang Tua Mahasiswa

\begin{tabular}{ccc} 
Pola Asuh & Frekuensi & Persentase (\%) \\
Demokratis & 165 & 73.3 \\
Permisif & 19 & 8.5 \\
Otoriter & 41 & 18.2 \\
\hline Total & 225 & 100 \\
\hline
\end{tabular}

Dari tabel 3 terlihat bahwa paling banyak mahasiswa diasuh dengan pola asuh demokratis dengan persentase $73.3 \%$, yaitu sebanyak 165 orang. Pola asuh otoriter mendapatkan persentase $18.2 \%$, yaitu sebanyak 41 orang dan pola asuh yang paling sedikit diterapkan pada responden adalah pola asuh permisif dengan persentase $8.5 \%$, yaitu sebanyak 19 orang.

Tabel 4. Distribusi Perilaku Integritas Akademik Mahasiswa

\begin{tabular}{ccc}
$\begin{array}{c}\text { Perilaku Integritas } \\
\text { Akademik }\end{array}$ & Frekuensi & Persentase (\%) \\
Kurang & 36 & 16 \\
Sedang & 154 & 68.4 \\
Baik & 35 & 15.6 \\
\hline Total & 225 & 100 \\
\hline
\end{tabular}

Berdasarkan tabel 4, terlihat bahwa perilaku integritas akademik terbanyak responden adalah sedang dengan persentase $68.4 \%$, yaitu sebanyak 154 orang. Perilaku integritas akademik kurang dan baik hanya berselisih satu orang responden. Perilaku integritas akademik kurang memiliki persentase 16\% dengan jumlah responden sebanyak 36 orang, dan perilaku integritas akademik baik memiliki persentase 15,6\% dengan jumlah responden sebanyak 35 orang.

\section{Analisis bivariat}

Analisis ini dilakukan untuk mengetahui hubungan antara variabel yang diteliti yaitu antara variabel independen dengan variabel dependen. Analisis bivariat dalam penelitian ini menggunakan uji Chisquare dengan taraf signifikansi $\alpha=5 \%$ dan interval kepercayaan 95\% untuk mengetahui hubungan antara variabel independen dengan variabel dependen. Jenis tabel yang digunakan adalah tabel $\mathrm{n} \times \mathrm{k}(3 \times 3)$ untuk variabel pola asuh orangtua dan kecerdasan emosional. Namun, karena syarat untuk uji Chi square tidak terpenuhi, maka peneliti melakukan uji alternatif yaitu dengan melakukan penggabungan sel.

Tabel 5. Hasil Analisis Bivariat Korelasi Pola Asuh Orang Tua dengan Perilaku Integritas Akademik Mahasiswa

\begin{tabular}{lrrrr} 
& \multicolumn{3}{c}{ Integritas Akademik } \\
\cline { 2 - 5 } Pola asuh & \multicolumn{2}{c}{ rendah } & \multicolumn{2}{c}{ baik } \\
\cline { 2 - 5 } orang tua & $\mathbf{n}$ & $\%$ & \multicolumn{1}{c}{$\mathbf{n}$} & $\%$ \\
& 20 & 12.1 & 145 & 87.9 \\
Demokratis & 7 & 36.8 & 12 & 63.2 \\
Permisif & 9 & 22 & 32 & 78 \\
Otoriter & 36 & 70.9 & 189 & 229.1 \\
\hline Total & & & & \\
\hline
\end{tabular}

Bila dilihat dari tabel 5, kita dapat melihat bahwa masing-masing pola asuh memiliki persentase yang lebih tinggi pada perilaku integritas akademik yang baik. Meskipun demikian, dapat kita lihat pula bahwa pada pola asuh otoriter, persentase perilaku integritas akademik kurang adalah 22\% dan pada pola asuh permisif persentase perilaku integritas akademik kurang adalah 36.8\%. Pada pola asuh demokratis, persentase perilaku integritas akademik kurang adalah $12.1 \%$. Pola asuh orang tua yang permisif dan pola asuh orang tua yang otoriter menunjukkan integritas akademik rendah yang lebih tinggi dibanding pada pola asuh yang demokratis. Hal ini sesuai dengan penjelasan Purwati dan Japar bahwa pola asuh yang yang 
demokratis menunjukkan perilaku buruk yang lebih rendah atau dapat lebih menekan perilaku kurang. ${ }^{11}$

Pola asuh permisif memiliki persentase perilaku integritas akademik kurang yang lebih tinggi dibandingkan pola asuh lainnya. Hal ini sesuai dengan penjelasan Purwati dan Japar bahwa anak yang dibesarkan dengan cara permisif memiliki karakteristik yang lebih labil, agresif dan berlaku semena-mena sesuka hati. ${ }^{11}$ Anak- anak yang diasuh dengan cara permisif akan sulit untuk memegang prinsip integritas akademik secara bertanggungjawab. Hal ini dikarenakan, mereka dibesarkan dengan kebebasan tanpa kontrol dan diberi sedikit tanggung jawab oleh orang tuanya. ${ }^{9}$

Persentase tingkat integritas akademik baik yang tertinggi dimiliki oleh pola asuh demokratis. Hal ini sejalan dengan penjelasan Sugihartono et al (2007) yang dikutip oleh Nurhayati ${ }^{12}$ bahwa anak yang dibesarkan secara demokratis akan tumbuh menjadi anak yang mudah beradaptasi, menghargai orang lain, dapat menerima kritik dan saran, serta stabil sehingga mereka akan memegang teguh prinsip integritas akademik dengan bertanggungjawab. Hal ini dikarenakan, orang tua yang demokratis akan memberikan tanggung jawab secara bertahap kepada sang anak hingga dia beranjak dewasa ${ }^{9}$

Berdasarkan hasil uji statistik Chi-Square didapatkan $\mathrm{P}$-value $=0.011$, sehingga dapat disimpulkan terdapat hubungan yang bermakna antara pola asuh orangtua dengan perilaku integritas akademik mahasiswa Fakultas Kedokteran. Hal ini sejalan dengan temuan pada penelitian Purwati dan Japar11 yang menyatakan bahwa masing-masing pola asuh yang diterapkan pada anak akan menghasilkan karakteristik yang berbeda-beda. Sejalan juga dengan penjelasan yang menyatakan bahwa sikap dan moral anak akan berbeda-beda bergantung dengan cara asuh orang tua masing-masing.9 Sedangkan, sifat kepribadian seseorang, yang juga dipengaruhi oleh pola asuh orang tua, adalah salah satu faktor endogen dalam pembentukan perilaku13

Hasil penelitian juga menunjukkan bahwa meskipun terdapat hubungan antara pola asuh dan integritas, namun pada semua jenis pola asuh persentase perilaku integritas akademik baik tetaplah yang paling tinggi. Hal ini juga sesuai dengan teori- teori dari berbagai ahli, bahwa selain pola asuh ada faktor-faktor lain yang mempengaruhi perilaku mahasiswa terhadap integritas akademik.

Keterbatasan pada penelitian ini adalah pada proses pengambilan data untuk uji validitas dan reliabilitas kuesioner pola asuh maupun untuk data yang akan diolah, peneliti menyebarkan kuesioner melalui internet yaitu menggunakan Google Drive atau kuesioner online dan menyebabkan peneliti tidak berinteraksi langsung dengan para responden. Hal tersebut dapat memberikan hasil validitas maupun reliabilitas yang berbeda bila dibandingkan dengan pengambilan kuesioner melalui interaksi langsung dengan responden

\section{KESIMPULAN}

Berdasarkan hasil penelitian dan pembahasan yang telah dijabarkan, dapat disimpulkan bahwa perilaku integritas akademik tingkat sedang merupakan perilaku integritas akademik mahasiswa Fakultas Kedokteran yang terbanyak. Pola asuh terbanyak yang diterapkan pada mahasiswa Fakultas Kedokteran adalah pola asuh demokratis, selain itu, pola asuh orang tua berkorelasi dengan perilaku integritas akademik mahasiswa Fakultas Kedokteran.

\section{SARAN}

Untuk masyarakat, disarankan untuk menerapkan pola asuh yang tepat kepada anak-anaknya. Pola asuh demokratis untuk saat ini adalah pola asuh terbaik yang dapat diterapkan kepada sang anak. Membesarkan atau mendidik anak dengan memberinya rasa tanggung jawab, kehangatan, ketegasan dan sikap penuh rasa kasih sayang yang seimbang akan membuat sang anak tumbuh menjadi manusia yang taat pada norma dan prinsip yang berlaku di berbagai bidang kehidupannya. Terlalu memanjakan atau terlalu bersikap keras tidak akan membuat sang anak tumbuh menjadi pribadi yang baik.

Untuk staff atau dosen Fakultas Kedokteran, meskipun perilaku integritas akademik pada mahasiswa secara garis besar adalah sedang, namun ada baiknya untuk terus ditingkatkan. Mengingat masih ada mahasiswa yang memiliki perilaku integritas akademik yang kurang, evaluasi berkala mengenai sangsi ataupun sosialisasi peraturan 
masih diperlukan. Mencari cara atau pendekatan lain agar mahasiswa dapat bersikap sesuai dengan peraturan juga dapat dilakukan pihak Fakulas Kedokteran, seperti pemberian sangsi yang lebih tegas, evaluasi dan perbaruan berkala mengenai peraturan yang telah dibuat, melakukan sosialisasi berkala mengenai peraturan dan sangsi kepada mahasiswa, dan cara-cara lainnya.

Untuk peneliti selanjutnya, integritas akademik merupakan suatu hal yang menarik untuk diteliti. Selain karena sifatnya yang sangat penting, faktorfaktor lain yang berkaitan dengan integritas akademik sangat banyak yang bisa untuk dibahas. Oleh karena itu, peneliti berharap pada penelitian selanjutnya dapat dibahas faktor-faktor lain selain pola asuh seperti peraturan akademik, tipe ujian, pengalaman masa lalu, dan faktor-faktor lain yang berkaitan dengan integritas akademik, khususnya pada mahasiswa kedokteran.

\section{UCAPAN TERIMAKASIH}

Ucapan terima kasih disampaikan kepada Ibu Lisa Musharyanti, MMedEd yang telah mengizinkan penggunaan kuesioner integritas akademik edisi Indonesia, Ibu Dra Cut Fauzia, M Biomed, Ibu Nurfitri Bustamam, SSi, MKes, M Biomed, dr. Sri Wahyunngsih, MKes, dr. Agneta Irmarahayu, MPdKed, dr Hanna Windyantini Reksodiwirjo MPdKed serta dr Anisah, MPdKed yang telah meluangkan waktu dan bersedia membahas modifikasi kuesioner integritas akademik agar lebih sesuai digunakan oleh mahasiswa Fakultas Kedokteran di tahap akademik.

\section{DAFTAR PUSTAKA}

1. Ronokusumo $S$, et al. Integritas Akademik "Sekedar Kata atau Nyata?". Jakarta: Badan Penerbit Fakultas Kedokteran Universitas Indonesia; 2012.

2. Hejri Z, Asghari F, Rashidian. Academic disintegrity among medical students: a randomized response technique study. Med Educ 2013:47:14453. Available from: https://search.ebscohost.com/

3. Taradi S, Taradi M, Dogas Z. Croatian medical students see academic dishonesty as an acceptable behavior: a cross sectional multicampus study. Journal of Medical Ethics [J Med Ethics] 2012;38(6):376-9. Available from: https://search.ebscohost.com/
4. Muktamiroh H, Prabandari YS, Sastrowijoto S. Hubungan Antara Kepribadian Dasar dan Kapasitas Mental dengan Persepsi, Perilaku, dan Intensi Integritas Akademik, Jurnal Pendidikan Kedokteran Indonesia. [internet] 2015;4(3) [cited 2016 Feb 22]. Available from: http://jurnal.aipki.net/

5. General Medical Council \& Medical Schools Council. Medical students:

6. Professional behaviour and fitness to practise, Guidance from the GMC and the MSC. 2007. [cited 2016 Feb 16] Available from: www.gmc-uk. org/education/.../professional_behaviour.asp

7. The International Center For Academic Integrity. The Fundametal Values Of Academic Integrity Second Edition, Clemson University; 2014. [cited 2016 Feb 16] Available from: www. academicintegrity.org

8. Musharyanti L, Rahayu GR, Prabandari YS, Jurnal Pendidikan Kedokteran Indonesia. [internet] 2012;1(3):200-11 [cited 2016 Feb 16]. Available from: http://jurnal.aipki.net/

9. Prianto RMA. Pengaruh Empati, Nurani dan Perkembangan Moral Ibu terhadap Perkembangan Moral Anak Melalui Gaya Pengasuhan Ibu, Disertasi Program Doktoral. Jakarta: Universitas Indonesia; 2006. Available from: http://www.lib. ui.ac.id/

10. Aisyah S. "Pengaruh Pola Asuh Orang Tua Terhadap Tingkat Agresivitas Anak", Jurnal MEDTEK. [internet] 2010 April;2(1). [cited 2016 Feb 22]. Available from: http://ft-unm.net/index. $\mathrm{php} /$ research.html

11. Sastroasmoro S, Ismael S. Dasar-dasar Metodologi Penelitian Klinis Edisi Ke-4, Jakarta: Sagung Seto; 2011.

12. Purwati JM. The Parents Parenting Pattern, Education, Jobs and Assistance to their Children in Watching Television and Aggressive Behaviour. International Education Studies, 2016;9(2). Available from: www.ccsenet.org/journal/index. php/ies/article/.../30740

13. Nurhayati DA. Pengaruh Pola Asuh Orang Tua dan Motivasi Belajar Siswa Terhadap Prestasi Belajar KKPI Kelas X Program Keahlian TKJ dan TAV di SMK PIRI 1 Yogyakarta, Skripsi Program Sarjana. Universitas Negeri Yogyakarta; 2013. [cited 2016 Feb 22] Available from: http://eprints.uny.ac.id/

14. Sunaryo. Psikologi untuk Keperawatan. Jakarta: EGC; 2006 [cited 2016 Maret 16] Available from: https://books.google.co.id/ 